\title{
Perovskite solar cells using polymer electrolytes
}

\begin{abstract}
This study deals with the characterization of methylammonium lead iodide (MAPbI3) material and the fabrication of perovskite solar cells using gel polymer electrolyte as the charge transport medium. The crystalline lead-based perovskite has been verified by $\mathrm{x}$-ray diffraction (XRD). The [100], [200], [210], [211], [220], [300] and [222] reflection planes can be observed at $2 \theta$ angles of $14.10^{\circ}, 28.35^{\circ}, 31.90^{\circ}, 34.95^{\circ}, 40.40^{\circ}, 43.15^{\circ}$ and $50.20^{\circ}$, indicating a cubic crystal symmetry for $\mathrm{CH} 3 \mathrm{NH} 3 \mathrm{PbI} 3$. EDX spectrum showed a $\mathrm{Pb}$ :I ratio of approximately 1:3 as in $\mathrm{CH} 3 \mathrm{NH} 3 \mathrm{PbI}$. The band gap for lead-based perovskite is $1.45 \mathrm{eV}$ estimated from UVVis absorption spectroscopy. The nanocrystalline MAPbI3 have been observed using field emission scanning electron microscopy (FESEM), where the average cuboid size of perovskite nanocrystals is $380 \mathrm{~nm}$. The cell have been fabricated using gel polymer electrolyte with composition 17.02 wt.\% PVA-13.93 wt.\% TBAI-0.96 wt.\% I2- 68.09 wt.\% DMF. The cell exhibits a power conversion efficiency (PCE) of $1.28 \%$ with open circuit voltage (Voc) 0.58 $\mathrm{mV}$, short circuit current density (Jsc) $3.74 \mathrm{~mA} \mathrm{~cm}-2$ and fill factor (FF) 59.18\%.
\end{abstract}

Keyword: Gel polymer electrolyte; Transport properties of charge carriers; Perovskite solar cell; FESEM; UV-Vis 